\title{
Towards a molecular mechanism underlying mitochondrial protein import through the
} TOM-TIM23 complex

Holly C. Ford, William J. Allen, Gonçalo C. Pereira*, Xia Liu, Mark S. Dillingham and Ian Collinson ${ }^{\dagger}$ School of Biochemistry, University of Bristol, Bristol BS8 1TD, UK

$\dagger$, corresponding author: $\underline{\text { ian.collinson@,bristol.ac.uk }}$

*, present address: MRC - Mitochondrial Biology Unit, University of Cambridge, The Keith Peters Building, Cambridge Biomedical Campus, Cambridge CB2 OXY, UK

\section{ABSTRACT}

Mitochondria contain over a thousand different proteins, which, aside from a few encoded on the mitochondrial genome, are translated in the cytosol and targeted for import. For the majority, the first port of call is the translocase of the outer membrane (TOM-complex); their onward journey is via a procession of alternative molecular machines, conducting transport to their final subcompartment destination: the outer-mitochondrial membrane (OMM), inner-mitochondrial membrane (IMM), inter-membrane space (IMS) or matrix. The pre-sequence translocase of the inner-membrane (TIM23-complex) is responsible for importing proteins with cleavable presequences, and comes in two distinct forms: the TIM23 ${ }^{\text {SORT }}$ complex mediates IMM protein insertion and the TIM23 $3^{\text {MOTOR }}$ complex is responsible for matrix import. Progress in understanding these transport mechanisms has, until recently, been hampered by the poor sensitivity and timeresolution of import assays. However, with the development of an assay based on split NanoLuc luciferase, we can now explore this process in greater detail. Here, we apply this new methodology to understand how $\Delta \psi$ and ATP hydrolysis, the two main driving forces for transport through the TIM23 $3^{\text {MOTOR }}$ complex, contribute to the import of pre-sequence-containing precursors (PCPs) with varying properties. Notably, we found that two major rate limiting steps define the PCP import time: passage of the PCP across the OMM and initiation of IMM transport by the pre-sequence. The rates of these steps are influenced by PCP properties such as size and net charge, but correlate poorly with the total amount of PCP imported - emphasising the importance of collecting rapid kinetic data to elucidating mechanistic detail. Our results also indicate that PCPs spend very little time in the TIM23 channel - presumably rapid success or failure of import is critical for maintaining mitochondrial health. 


\section{INTRODUCTION}

3 Mitochondria are eukaryotic organelles responsible for the biosynthesis of ATP and many other 4 essential cellular functions: biosynthesis of fatty acids (Nowinski et al., 2018) and Fe-S clusters 5 (Rouault, 2012), calcium regulation (Nicholls, 1978), generation of reactive oxygen species (ROS)

6 (Chen et al., 2003)(Nishikawa et al., 2000), intracellular signalling (Hoth et al., 1997)(Chandel,

7 2015), and apoptosis (Wang and Youle, 2009). Owing to their double-membrane, mitochondria 8 comprise four distinct compartments: the outer-mitochondrial membrane (OMM), inter-membrane space (IMS), inner-membrane (IMM), and matrix. The IMM is highly specialised for the chemiosmotic mechanism of aerobic respiration; it is impermeable to ions and maintains an

11 electrochemical gradient of protons (acidic and positive on the IMS side) - the proton-motive force 12 (PMF). This serves as a form of potential energy, composed of an electrical $(\Delta \psi)$ and a chemical $13(\Delta \mathrm{pH})$ component, used to drive the rotary mechanism of ATP synthesis inter alia.

Of more than a thousand proteins that constitute the mitochondrial proteome, all but a handful 16 encoded on the mitochondrial genome (13 in human), are synthesised in the cytosol. A number of 17 bespoke protein import machineries have evolved to transport this highly diverse mixture of soluble and membrane-associated proteins to their various submitochondrial destinations, and for their subsequent folding and assembly into multi-protein complexes. Almost all mitochondrial precursor proteins enter mitochondria via the translocase of the outer membrane (TOM complex)

21 which contains the pore-forming $\beta$-barrel protein, Tom40. The TOM complex in Saccharomyces cerevisiae is thought to form dimers, and possibly trimers and tetramers, and notably their pores

23 have highly negatively charged inner surfaces (Tucker and Park, 2019)(Araiso et al., 2019).

Roughly $60-70 \%$ of mitochondrial precursor proteins - almost all those targeted to the matrix and a subset of IMM proteins - have a positively-charged, amphipathic $\alpha$-helical pre-sequence, also known as a mitochondrial targeting sequence (MTS) (Araiso et al., 2019)(Vögtle et al., 2009). These pre-sequence-containing precursors (PCPs) are transferred to the translocase of the inner 29 membrane (TIM23-complex) once their N-termini emerge from the Tom40 channel, and pass 30 through in an unfolded state (Eilers and Schatz, 1986)(Matouschek et al., 1997)(Neupert and 31 Brunner, 2002)(Rassow et al., 1990) (Neupert and Herrmann, 2007). Genetic and biochemical 
1 experiments have elucidated the key constituents of the TIM23-complex (Blom et al., 1993)

2 (Maarse et al., 1992) (Emtage and Jensen, n.d.) (Maarsea et al., 1994): the core (TIM23 ${ }^{\mathrm{CORE}}$ )

3 comprises three membrane-spanning proteins: Tim23, Tim17 and Tim50. Tim23 is the channel-

4 forming protein and has 4 trans-membrane $\alpha$-helices (TMH) and a hydrophilic $\mathrm{N}$-terminal region

5 projecting into the IMS which can bind to pre-sequences. Tim17 is required by Tim 23 for

6 structural integrity, while the large IMS domain of Tim50 provides the main receptor for PCPs.

7 TIM23 $3^{\mathrm{CORE}}$ associates with different proteins to form complexes tailored to different tasks:

8 together with Tim21 and Mgr2 it forms the TIM23 ${ }^{\text {SORT }}$ complex, capable of lateral release of

9 proteins with hydrophobic sorting sequences, while association with the pre-sequence translocase-

10 associated motor (PAM) forms the TIM23 $3^{\mathrm{MOTOR}}$ complex, responsible for matrix import. After

11 crossing the IMM, either way, the MTS is cleaved by a matrix processing peptidase (MPP) (Vögtle

12 et al., 2009).

14 Both pathways into and across the IMM have been shown to require the electrical component of

15 the PMF, the membrane potential $(\Delta \psi)$, for transport - as an electrophoretic force on the positively

16 charged pre-sequence (Martin et al., 1991)(Geissler et al., 2000)(Truscott et al., 2001). $\Delta \psi$ alone

17 is sufficient for insertion of membrane proteins via the TIM23 ${ }^{\text {SORT }}$ complex (Callegari et al., 2020),

18 but complete import into the matrix by the TIM23 ${ }^{\text {MOTOR }}$ complex requires an additional driving

19 force - ATP hydrolysis by the main component of PAM, the mtHsp70 protein (Ssc1 in

20 yeast)(Wachter et al., 1994). The remaining proteins belonging to PAM facilitate its dynamic

21 assembly at the matrix face of the import channel and ensure tight regulation of the ATPase activity

22 of mtHsp70. $\Delta \psi$ has also been implicated in other aspects of TIM23 $3^{\text {MOTOR }}$-mediated PCP import.

23 It promotes Tim23 dimerisation (Bauer and Sirrenberg, 1996), necessary for PCP binding, and is

24 required for Tim17-mediated opening of the channel, which in turn allows the recruitment of

25 Hsp70 by Tim44 (S et al., 2007)(Demishtein-Zohary et al., 2017)(Ting et al., 2017)(Ramesh et al.,

26 2016).

28 Our basic understanding of the mechanism of protein import via the TOM-TIM23 ${ }^{\text {MOTOR }}$-complex

29 is summarised in Fig. 1A. The unfolded or chaperone-bound PCP binds to the TOM receptor,

30 Tom20, in the OMM. This is followed by sequential: threading and passage of the PCP through

31 the Tom40 channel, transfer to the TIM23 complex in the IMS/ IMM, $\Delta \psi$-dependent translocation 
1 of the pre-sequence into the matrix, and ATP-dependent translocation of the remainder of the

2 protein. This model is primarily derived from end point measurements from a classical import assay involving autoradiography or Western blotting. However, this method is highly limited in

4 its time resolution, and insufficient to provide a deep understanding of the individual steps that

5 make up transport, or their relative contributions to its kinetics. For this reason, we recently

6 developed a highly time-resolved and sensitive assay which exploits a split NanoLuc enzyme

7 (Pereira et al., 2019) to measure protein transport across membranes (Fig. 1B).

In the NanoLuc assay, PCPs tagged with a small fragment of the NanoLuc enzyme (an 11 amino acid peptide called pep86), are added to mitochondria isolated from yeast engineered to contain a

11 matrix-localised large fragment of the enzyme (the enzyme lacking a single beta strand, called

12 11S). When the PCP-pep86 fusion protein reaches the matrix, pep86 binds rapidly and with tight

13 affinity to $11 \mathrm{~S}$ forming a complete NanoLuc luciferase. In the presence of the NanoLuc substrate

14 (furimazine), this generates a luminescence signal proportional to the amount of NanoLuc formed.

15 Luminescence is thus a direct readout of the amount of PCP that has entered the matrix, up to the

16 total amount of $11 \mathrm{~S}$. As expected, it is $\Delta \psi$-dependent, affected by depletion of ATP, and sensitive

17 to specific inhibitors of TIM23-dependent protein import (Pereira et al., 2019).

Here, we have used the NanoLuc translocation assay to obtain precise, time-resolved measurements of protein delivery into the matrix mediated by the TOM and TIM23 $3^{\text {MOTOR }}$

21 complexes. To add mechanistic detail to the above model (Fig. 1A), we systematically varied the

22 length and charge of the mature sequences of PCPs and profiled their import kinetics. To better

23 understand the cause of any observed effects on amplitude, rate and lag, we performed experiments

24 under conditions where either of the two main driving forces, $\Delta \psi$ or ATP, had been depleted. Our

25 results suggest that IMM transport itself is fast in normally functioning mitochondria, and limited

26 by the availability of $\Delta \psi$. Analyses such as these, together with emerging structures of the import 27 machinery (Tucker and Park, 2019), will be fundamental to understanding the underlying 28 molecular basis of mitochondrial protein import.

\section{RESULTS}




\section{Basic characterisation of protein import suggests under experimental conditions the reaction}

2 is largely single turnover

3 An exemplar NanoLuc import trace is shown in Fig. 1C, collected using the model yeast matrix

4 protein Acp1 (used in previous import studies as a matrix-targeted precursor (Wurm and Jakobs, 5 2006)) fused to a pep86 (Acp1-pep86). The most intuitive parameter of this trace is amplitude, which corresponds to the amount of NanoLuc formed when the reaction reaches completion, and thus the total number of import events; so long as the pep86 tag does not exceed matrix 11S. In order to verify that this was not the case we estimated the concentration of $11 \mathrm{~S}$ in the mitochondria by quantitative Western blotting. An antibody raised against $11 \mathrm{~S}$ was used to compare the quantities of the mitochondrial contained luciferase with known quantities of the purified protein

11 (Fig. S1A). The results reveal high $(\mu \mathrm{M})$ internal 11S concentrations of with significant variation 12 between mitochondrial preparations $(\sim 2.8-7.5 \mu \mathrm{M})$. We see no correlation between amount of $1311 \mathrm{~S}$ and signal amplitude even with saturating PCP (Fig. S1B-C, and see below). Thus, we 14 conclude that the matrix concentration of $11 \mathrm{~S}$ is far in excess of the imported PCP, regardless of how much of it is added to the outside.

17 We next measured signal amplitude over a wide range of concentrations of Acp1-pep86. Plotting 18 the results shows that amplitude is linearly related to PCP concentration up to $\sim 45 \mathrm{nM}$, where it plateaus (Fig. 2A). Because the mitochondrial matrix volume is only $\sim 1 / 12,000$ of the total reaction volume (see Methods), if all $45 \mathrm{nM}$ PCP were imported it would correspond to roughly $540 \mu \mathrm{M}$

21 inside the matrix. This is not only far in excess of the internal $11 \mathrm{~S}$ concentration (as low as $\sim 2.8$

$22 \mu \mathrm{M}$ ), but is also implausible simply from the amount of physical space available. Evidently, 23 therefore, only a tiny fraction of the PCP added reaches the matrix.

As neither the amount of PCP added nor the amount of 11S in the matrix appear to be limiting, we next tested to see whether the number of import sites might be having an effect. To estimate the 27 number of import sites, we generated a PCP that can import and give a signal, but which prevents 28 subsequent import events through the same import site - i.e. forcing single turnover conditions. 29 To do this, we fused dihydrofolate reductase (DHFR) to the PCP which, in the presence of the 30 inhibitor methotrexate (MTX), folds tightly and cannot be imported (Gold et al., 2017). As 31 expected, if DHFR is positioned N-terminal to pep86 (DHFR-pep86), we see very little 
1 luminescence with MTX present, consistent with blocked import (Fig. 2B). However, when DHFR

2 is positioned C-terminal to pep86 (pep86-DHFR) with sufficient length between the two to span

3 the TOM and TIM complexes (212 amino acids in this case, longer than the 135 required (Rassow

4 et al., 1989)), we do see an import signal (Fig. 2B), confirming that NanoLuc can form as soon as

5 pep86 enters the matrix. Surprisingly, the presence or absence of MTX makes only a minor

6 difference to the amplitude of this signal (Fig. 2B).

8 Signal amplitude as a function of the pep86-DHFR PCP concentration with or without MTX shows

9 a similar but not identical relationship (Fig. 2C). The slope, which corresponds to the increase in

10 amplitude per $1 \mathrm{nM}$ PCP, is 1.22 times greater in the absence of MTX, meaning only about 20\%

11 of the signal arises from turnovers beyond the first. While this does not necessarily mean that

12 import is strictly single turnover - which seems unlikely for fully functional mitochondria - it does

13 suggest that it behaves as single turnover under the reaction conditions here.

\section{Kinetic analysis of import suggests two major rate-limiting steps}

17 In addition to the amplitude data, the import traces contain information about the kinetics of the

18 reaction. Looking again at the data from in Fig. 1C, it can be seen that import does not start at its 19 maximum rate; in most cases there is a lag before transport accelerates. This is characteristic of 20 reactions with multiple consecutive steps, where only the last one gives rise to a signal. As an 21 approximation, the data fit well to a closed equation for a two-step process (see Methods), which 22 gives two apparent rate constants $\left(k_{1}{ }^{\prime}\right.$ and $\left.k_{2}{ }^{\prime}\right)$ in addition to amplitude (Fersht, 1984).

24 In the simplest case possible, where the two steps are irreversible and have very different values, $25 k_{1}{ }^{\prime}$ and $k_{2}{ }^{\prime}$ correspond to the two rates for these steps $\left(k_{1}\right.$ and $\left.k_{2}\right)$ (Fersht, 1984). This is complicated 26 if the reactions are reversible (in which case the reverse rates also factor), or if $k_{1}$ and $k_{2}$ are very 27 similar (in which case they are both convoluted into $k_{1}{ }^{\prime}$ and $k_{2}{ }^{\prime}$ ). Nonetheless, this analysis is very 28 useful for understanding the mechanism of import (see below) - especially under conditions where $29 k_{1}$ and $k_{2}$ are well separated. 
1 It should be noted that the order of the two steps cannot be determined a priori, but we expect the 2 first rate to be dependent on PCP concentration, as association of TOM and PCP is the first step 3 in the transport process. It is also important to note that any additional step faster than about $5 \mathrm{~min}^{-}$

$4 \quad{ }^{1}$ will not be resolved in our experimental set up using deploying a multi-plate reader (Fig. S2A), and will instead manifest as a small apparent lag before the signal appears (equal to $1 / k_{\text {step, where }}$ $k_{\text {step }}$ is the rate constant for that process)(Allen et al., 2020). This includes formation of NanoLuc as this is $>7.4 \mathrm{~min}^{-1}$ even at the lowest estimated $11 \mathrm{~S}$ concentration, as determined in solution (Fig. S2B). As expected, the internal concentration of $11 \mathrm{~S}$ does not appreciably affect transport kinetics (Fig. S2C).

\section{Transport is dependent on total protein size}

13 To begin to determine what the two apparent rates correspond to, we first designed and purified 14 two series of four PCPs, varying either in total length or $\mathrm{N}$ - to C-terminal positioning of pep86 15 (Fig. 3A). The length variants all similarly contained the pre-sequence of Acp1 followed by the 16 Acp1 mature domain, with pep86 (L) at the C-terminus. Increase in length was achieved by 17 repeating the mature part of Acp1 up to three times. In between each Acp1 mature domain we 18 included a scrambled pep86 sequence (D), which does not interact with 11S (Allen et al., 2020), 19 such that each tandem repeat has the same overall amino acid (aa) composition. This protein set 20 was designed to reveal potential PCP size-dependence of import. The other set (sequence variants) 21 were all identical to the longest length-variant PCP (four tandem repeats), but with the active pep86

22 in different positions. Because the sequence variants (abbreviated as LDDD, DLDD, DDLD and 23 DDDL) are identical save for number of aa that must enter the matrix before the NanoLuc signal 24 does, differences in import kinetics between them should reflect processive translocation through the TOM-TIM23 ${ }^{\text {MOTOR }}$ complex (the ATP-dependent step in Fig. 1A).

27 Transport of all four length variants (L, DL, DDL and DDDL) and sequence variants (LDDD, 28 DLDD, DDLD and DDDL) at high concentration $(1 \mu \mathrm{M})$ fit well to the simple two-step model, 29 giving an amplitude and two apparent rate constants (assigned arbitrarily $k_{1}{ }^{\prime}$ and $k_{2}{ }^{\prime}$ ) for each. 30 Import traces and the results of fits to the two-step model are plotted in Fig. 3B and C respectively, 31 with error bars representing the SEM from three biological replicates. 
2 For the length series, signal amplitude is inversely correlated with protein length (Fig. 3C). This

3 is not because the PCPs become trapped in the import channel during transport, as the sequence

4 variants all have the same amplitude (Fig. 3C). Instead, it seems that small proteins are able to

5 accumulate at higher levels in the matrix than large ones. This is consistent with the idea that

6 energy depletion limits import - it takes more energy to import a larger protein - rather than a

7 limitation of the amount of $11 \mathrm{~S}$, as this would result in the same maximum amplitude for all

8 proteins. In terms of rates, we find that the faster rate constant $\left(k_{1}{ }^{\prime}\right)$ has a strong inverse correlation

9 with PCP length (but not pep86 position), i.e. it is faster for smaller proteins, while $k_{2}{ }^{\prime}$ shows little

10 effect.

12 To explore the length and sequence variants further, we measured protein import for both protein 13 sets over a range of PCP concentrations, and fitted the data in the same way (Fig. 4). Just as before, 14 we find no systematic difference between the sequence variants (Fig. 4D-F) - clearly passage of 15 the PCP through TIM is not limiting the overall transport rate. For the length series, however, the 16 apparent $\mathrm{K}_{\mathrm{d}}$ for import increases as PCP length increases; effectively, more PCP must be added to 17 produce the maximum amplitude (Fig. 4A), even though that amplitude is lower (Fig. 3B-C). It is 18 difficult to estimate accurate $\mathrm{K}_{\mathrm{MS}}$ for the fitted rate constants as they are hard to assign when they 19 are very similar, but it appears the slow rates $\left(k_{2}^{\prime}\right)$ have approximately the same apparent $\mathrm{K}_{M}$ as 20 amplitude, while the fast rates $\left(k_{1}{ }^{\prime}\right)$ all have a similar apparent $\mathrm{K}_{\mathrm{M}}$, in the low $100 \mathrm{~s}$ of $\mathrm{nM}$.

\section{Depletion of $\Delta \psi$ has a stronger effect on import than depleting ATP}

23 To better understand the molecular basis for the length-dependence of import, we measured import 24 of the length and sequence variants under conditions in which each of the two driving forces $(\Delta \psi$ and ATP) were depleted. Partial depletion of $\Delta \psi$ by pre-treatment of mitochondria with valinomycin, a potassium ionophore, causes a decrease in signal amplitude for all lengths and sequence variants, affecting them roughly equally (Fig 5A). Intriguingly, valinomycin has very different effects on the two apparent rate constants: $k_{1}{ }^{\prime}$ is somewhat slowed for shorter proteins but

29 largely unaffected for longer ones (Fig. 5A), while $k_{2}^{\prime}$ is somewhat slowed for short proteins but 30 dramatically reduced for longer ones (Fig. 5A). 
1 Depletion of matrix ATP was achieved simply by excluding ATP and its regenerating system from

2 the assay buffer. Endogenous matrix ATP under these conditions is minimal, as is evident from

3 the fact that import becomes highly sensitive to antimycin A, an inhibitor of oxidative

4 phosphorylation (Fig. S3). This sensitivity arises because ATP is required for hydrolysis by the

5 ATP synthase to maintain $\Delta \psi$ in the absence of oxidative phosphorylation(Campanella et al.,

6 2008). Import experiments performed with depleted ATP show reduced amplitude, but unlike

7 valinomycin this effect is more pronounced for the longer PCPs (Fig. 5B) - consistent with

8 proposed role for ATP in promoting transport of the mature part of the PCP. ATP depletion has

9 little or no effect on $k_{1}{ }^{\prime}$, and a relatively minor effect on $k_{2}{ }^{\prime}$ (Fig. 5B), affecting both the length and

10 sequence variants roughly equally.

\section{A simple working model for transport based on the above results}

13 Taking all the above observations together, we can propose a simplified model for import that 14 incorporates two major rate-limiting steps. Because $k_{2}^{\prime}$ is somewhat sensitive to ATP, it most likely comes at the end of transport, as the contribution of Hsp70 requires at least some of the PCP to be

16 in the matrix. Since $k_{2}{ }^{\prime}$ shows very little dependence on PCP length in fully energised 17 mitochondria, we propose that it is primarily the $\Delta \psi$-dependent insertion of the pre-sequence through TIM23, not the subsequent passage of the unfolded passenger domain that is limiting

19 (although both presumably contribute the apparent rate constant). However, under conditions of $20 \Delta \psi$ depletion, a length-dependence of $k_{2}{ }^{\prime}$ emerges: this is consistent with import rate of the rest of 21 the PCP being affected by $\Delta \psi$ ((Schendzielorz et al., 2017), and see also below). It is also possible 22 that transport of longer PCPs has a higher chance of failure, with the PCP slipping back into the 23 IMS - this would be a useful mechanism to prevent TIM23 complexes becoming blocked with 24 defective PCPs, and would explain the difference in the effect of $\Delta \psi$ depletion on the length and 25 sequence variants.

27 The other apparent rate constant, $k_{1}{ }^{\prime}$, is strongly dependent on PCP concentration (Fig. 4), however 28 this saturates with an apparent $\mathrm{K}_{\mathrm{M}}$ of around 100-200 $\mathrm{nM}$. This is indicative of a two-step process, 29 where the first is PCP binding and dissociating in rapid equilibrium (too fast to measure as a step 30 in itself), followed by a slower step that proceeds from the bound form: 


$$
P C P+T O M \underset{k_{o f f}}{\stackrel{k_{o n}}{\rightleftarrows}} \text { TOM.PCP } \stackrel{k_{1}}{\rightarrow} \text { TOM.PCP* }
$$

3 The strong dependence of $k_{1}{ }^{\prime}$ on PCP length provides a clue as to the nature of $k_{1}-$ it is likely to 4 correspond to passage of the PCP across the OM, through the TOM complex.

Putting all of this together, we propose the following minimal kinetic scheme for PCP import:

$$
\text { PCP } \text { out }+ \text { TOM } \underset{k_{\text {off }}}{\stackrel{k_{\text {on }}}{\rightleftarrows}} \text { TOM.PCP } P_{\text {out }} \stackrel{k_{1}}{\rightarrow} \text { TOM.PCP IMS } \stackrel{k_{2}}{\rightarrow} \text { PCP } \text { in }
$$

where the subscript to PCP indicates its location (outside the OM, in the IMS, or inside the matrix).

11 In this model, $k_{\text {on }}$ and $k_{\text {off }}$ are both fast compared with $k_{1}$, and give an affinity $\left(\mathrm{K}_{\mathrm{d}}=k_{\text {off }} / k_{\text {on }}\right)$ in the 12 order of $100 \mathrm{nM}$, similar to the affinity $(\sim 35 \mathrm{nM})$ of a bacterial secretion preprotein to bacterial 13 inner membrane vesicles (Hartl et al., 1990). The two extracted rate constants can be 14 approximately determined as ([PCP] designates PCP concentration):

$$
k_{1}{ }^{\prime} \sim k_{1} \frac{[P C P]}{K_{d}+[P C P]} \quad \text { and } \quad k_{2}{ }^{\prime} \sim k_{2}
$$

This model fits the data, and we believe it is the most reasonable interpretation of the above experimental results. However it still leaves open several questions, notably the extent to which $k_{1}$ and $k_{2}$ are reversible. For example, the fact that $k_{1}{ }^{\prime}$ is somewhat affected by valinomycin (Fig. 5A) suggests that $k_{1}$ is to some extent reversible, given that passage through TOM can occur in the absence of $\Delta \psi$ (Mayer et al., 1993)(Lill et al., 1992): slowing $k_{2}$ would then leave more opportunity

23 diffusion back out of the IMS through TOM, a process that occurs in the absence of ATP

24 (Ungermann et al., 1996). In addition, we cannot determine from this data exactly at what stage handover from TOM to TIM23 occurs, whether the entire PCP must pass through TOM first, or even whether it can dissociate from TOM before binding to TIM23.

\section{Changing PCP net charge affects import amplitude and rate differently}

$29 \Delta \psi$, the electrical component of the PMF (positive outside), has been proposed to act primarily upon positively charged residues in the PCP, pulling them through electrophoretically (Martin et 
1 al., 1991)(Geissler et al., 2000)(Truscott et al., 2001). To test this idea, we designed a series of

2 proteins, based on a engineered version of the N-terminal section of yeast cytochrome $b_{2}$ lacking

3 the stop-transfer signal ( $\Delta 43-65)$ to enable complete matrix import (Gold et al., 2014), with varying

4 numbers of charged residues (Fig. 6A). These proteins were of the same length, but spanned 5.43

5 units of pI ranging from 4.97 to 10.4 . Import of these charge variants under saturating conditions

6 (1 $\mu \mathrm{M}$ PCP) was measured using the NanoLuc assay as above (Fig. 6B).

8 The most immediately striking observation is that amplitude is strongly inversely correlated with net charge of the PCP - i.e. the opposite of what might be expected given the direction of $\Delta \psi$ (Fig. 6C). To understand why this would be, we turned to our earlier interpretation of signal amplitude:

11 that it is limited by the availability of $\Delta \psi$. If transport of positively charged residues depletes $\Delta \psi$ 12 while transport of negatively charged residues replenishes it, this could explain why negatively 13 charged proteins accumulate to a higher level.

15 To test this hypothesis, we monitored $\Delta \psi$ in isolated mitochondria over time by measuring TMRM

16 fluorescence, then assessed the effect of adding the PCPs with differing net charge (Fig. 6D). The

17 PCPs did indeed cause strong depletion of $\Delta \psi$ and, moreover, this effect diminished with increasing net negative charge. Increasing net positive charge did not seem to result in enhanced depletion of $\Delta \psi$, but TMRM does not resolve $\Delta \psi$ well in this range, so this does not necessarily mean that this effect is not occurring. A second prediction from this hypothesis is that membrane

21 depolarisation prior to protein import will abolish the correlation between net charge and

22 amplitude. This is indeed exactly what we see: valinomycin reduces amplitudes for all PCPs, but 23 the effect is greater for more negatively charged PCPs, bringing all amplitudes to about the same 24 level (Fig. 6E). Depleting ATP, meanwhile, has very little effect on amplitude, just as for the Acp125 based PCPs.

27 Looking at the import traces for the charge series, it is clear that positively charged PCPs are 28 imported much faster than negatively charged ones (albeit reaching a lower final amplitude; Fig. 29 6B-C). This is again consistent with $\Delta \psi$ specifically assisting the transport of positively charged 30 residues. Unlike the length variants based on Acp1, however, not all of the import traces from the 31 charge variants fit to the two step model (Fig. 6B). While the more negatively charged ones have 
1 a clear lag before reaching their maximum rate, the positively charged ones appear to have only a

2 single rate-limiting step, or even to have a burst of rapid import, followed by a slower phase (Fig.

$36 \mathrm{~B}$ ). Because steps are only resolved on the plate reader if they are $\leq$ about $5 \mathrm{~min}^{-1}$, the most likely

4 explanation for this is that one phase has become too fast to measure. This is most likely transport

5 through TIM23, which is strongly $\Delta \psi$-dependent and thus presumably faster for more positively

6 charged proteins. A burst suggests multiple turnovers, with the first one very fast, and subsequent

7 ones limited by a slower resetting of TIM23 (see Discussion).

Testing the above results with native PCPs

10 While the use of artificial PCPs, as above, allows their properties to be varied in a systematic 11 manner, it is possible that these modifications will affect native features with fundamental roles in 12 the import process. To confirm that the above observations hold true for native PCPs we performed 13 import experiments with four pep86-tagged native PCPs differing in length and charge. We chose 14 the $F_{1} \alpha$ and $F_{1} \beta$ subunits of the mitochondrial ATP synthase, both large proteins $(>500$ amino 15 acids) with mature amino acid sequences differing in predicted $\mathrm{pI}$ by $\sim 1.55\left(\mathrm{~F}_{1} \beta=5.43\right.$ and $\mathrm{F}_{1} \alpha$ 16 =6.98); and two smaller proteins (<200 amino acids), Acp1 and Mrp21, with predicted mature 17 sequence pIs of 4.87 and 10.00 respectively (Fig. 7A).

19 Consistent with our earlier results, we see higher amplitudes for the shorter and more negatively 20 charged PCPs (Fig. 7B), and faster transport of the shorter PCPs than the longer ones (Fig. 7B).

21 The effect of net charge holds true for the larger PCPs, which both have clear two-step transport 22 (Fig. 7B), but the small PCPs appear to have only a single rate-limiting step, and do not differ 23 significantly in import rate (Fig.7B). Presumably the charge dependence only becomes measurable 24 when transport through TIM23 is slow enough to be appreciable. Overall, these results suggest 25 that the data collected with artificial PCPs will hold true for native ones as well.

\section{DISCUSSION}

29 Protein import into mitochondria is, by nature, a complicated process with machineries in two 30 membranes having to coordinate with one another as well as with parallel import pathways to 31 deliver a wide range of proteins to their correct destinations. Here, we have built a basic 
1 mechanistic model of one of the major import routes - the TOM-TIM23 ${ }^{\text {MOTOR }}$ pathway of matrix

2 proteins - using a high-resolution import assay based on NanoLuc. Our results suggest that two

3 major events are responsible for the majority of the PCP transit time: passage of the PCP through

4 the TOM complex and initiation of import by insertion of the pre-sequence through the

5 TIM23 ${ }^{\text {MOTOR }}$ complex. By contrast, the initial binding of PCP to TOM is fairly rapid, as is passage

6 of the mature PCP domain through TIM23. Crucially, the rates of the different steps correlate very

7 poorly with the amount of PCP in the matrix when the reaction ends, which has always been the

8 conventional readout of import. It therefore seems that this pre-steady-state kinetic approach will

9 be critical in the future, both for further dissecting import via the TOM-TIM23 ${ }^{\text {MOTOR }}$ complex and

10 for understanding the other pathways that together comprise the mitochondrial protein import

11 machinery.

13 Import appears to be largely single turnover under our experimental conditions, that is each import 14 site only imports a single PCP. While this is fortuitous in that it allows us to access pre steady15 state events easily, it is incongruent with mitochondrial protein import in vivo. We propose that, 16 under experimental conditions, transport is limited by the amount of energy available in the form 17 of $\Delta \psi$. Indeed, measurements of $\Delta \psi$ using TMRM confirm that PCP import causes a depolarisation 18 of the IMM that is not restored. Also consistent with $\Delta \psi$ being consumed, we find that the PCPs 19 that require more total energy to import (such as longer ones), or that are likely to consume more $20 \Delta \psi$ (positively charged ones) reach a lower concentration in the mitochondrial matrix. The 21 mechanism by which $\Delta \psi$-depletion leads to single turnover conditions is likely to relate to the 22 requirement of $\Delta \psi$ for dimerization of TIM23 and recruitment of Tim44, both required for delivery 23 to the matrix. As PCPs bind only to dimeric TIM23 complexes and, during transport, disrupt this 24 conformation, loss of $\Delta \psi$ would prohibit the resetting of the TIM23 complex to allow turnovers 25 after the first (Bauer and Sirrenberg, 1996). With some of the faster transporting PCPs we do 26 indeed see a rapid burst of import followed by a slower phase, as would be expected for multiple 27 turnovers where the first is fast. This could therefore provide a window for future studies to 28 investigate this priming event.

30 Previous studies have shown that the TOM-complex is in excess over TIM23, with $1 \mathrm{mg}$ yeast 31 mitochondria containing $\sim 17-20$ pmol TIM23 ( $\sim 9-10$ pmol dimer) and estimations of between 85 
1 and 250 pmol TOM40 (Sirrenberg et al., 1997)(Dekker et al., 1997). In our experiments, this

2 TIM23 dimer concentration equates to $\sim 62.5$ fmol per well $\left(10\right.$ pmol.mg-1 $\left.\times 50 \mu \mathrm{g} \cdot \mathrm{ml}^{-1} \times 125 \mu \mathrm{l}\right)$

3 - similar to the estimated amount of 11S ( 28-76 fmol per well, based on an estimated 4.46-12.17

4 pmol.mg-1). This close correspondence presumably explains why we find that $11 \mathrm{~S}$ is not limiting,

5 but intriguingly, it also suggests that each import site only imported on average one 11S, even

6 though 11S import occurred in live yeast before mitochondrial isolation. This correspondence may

7 not be coincidental; if the number of TIM23 sites limited import, this could be calibrated as a

8 regulatory mechanism to avoid proteotoxic stress.

10 The transfer of PCPs from TOM to TIM23 is thought to involve cooperative interactions of 11 subunits of the two complexes (Callegari et al., 2020). But the extent to which transport of PCPs 12 across the OMM and IMM is coupled, remains unknown. It has been suggested that the rate of 13 PCP passage through the OMM is one factor that determines whether PCPs are transferred to the 14 matrix or released laterally into the IMM (Harner et al., 2011), implying simultaneous and cooperative activities of TOM and TIM23. PCPs have been captured spanning both membrane 16 complexes at the same time in super-complexes of $\sim 600 \mathrm{kDa}$ (Dekker et al., 1997)(Gold et al., 17 2014)(Chacinska et al., 2010). Moreover, it has been proposed that Tim23 has a topology spanning 18 the OMM as well as the IMM, with its N-terminus domain exposed on the cytosolic face of the 19 OMM, and is thus thought to act as a tether (Donzeau et al., 2000), presumably increasing import 20 efficiency. These proximal associations of TOM and TIM23 suggest that import through TOM 21 does not have to be complete before import through TIM23 can begin.

However, there is also evidence to suggest that the TOM and TIM23 complexes can transport 24 PCPs independently, in steps that are not necessarily concurrent. Matrix import of PCPs has been observed in mitoplasts (Hwang et al., 1989)(Ohba and Schatz, 1987), in which the OMM has been removed, suggesting that a handover from TOM is not absolutely required. The in vivo existence 27 of TOM-TIM23 super-complexes is unconfirmed. They have been detected only when engineered 28 PCPs with C-terminal domains that cannot pass through TOM are used (Chacinska et al., 2003). 29 And only under these artificial conditions do TOM and TIM23 subunits co-immuno-precipitate 30 (Horst et al., 1995). Their assembly must be dynamic and transient. Moreover, the N-terminal 
1 domain of Tim23, that tethers the IMM and OMM, is not required for either PCP import though

2 TIM23, or TOM-TIM23 super-complex formation (Chacinska et al., 2003).

4 Our results also hint that this handover is not absolutely required. The data here suggest that 5 transport of a PCP through TOM is reversible, and therefore possible in the absence of TIM23 activity. Reverse transport of proteins through TOM, and in some cases also through TIM23, has

7 been observed previously, although this process is not well understood. Proteins that are reduced 8 or conformationally unstable in the IMS can retro-translocate to the cytosol via TOM40, and the efficiency of this process is relative to protein size (both linear length and 3D complexity); smaller

10 proteins are more efficiently retro-translocated (Bragoszewski et al., 2015). Under physiological 11 conditions, PINK1 is cleaved in the IMM by PARL, releasing the remaining C-terminal region for 12 release back to the cytosol for proteosomal degradation. But the process is not well understood, 13 such as if, and how, it is regulated, and if a driving force is required. Additionally, we see some 14 PCP concentration dependence of $k_{2}{ }^{\prime}$; if direct interaction of TOM with TIM23 were strictly 15 required then $k_{2}$ would not be affected by PCP concentration, but if PCP can accumulate in the 16 IMS this would explain our finding.

Overall, the above analysis provides good estimates of the two rate limiting steps for import, and provides evidence as to the constraints that act upon the others. If a few of the above questions are resolved, we believe it should be possibly to construct a complete kinetic model of mitochondrial import, as has been recently achieved for the bacterial Sec system (Allen et al., 2020).

MATERIALS AND METHODS

\section{Strains and plasmids}

26 E. coli $\alpha$-select cells were using for amplifying plasmid DNA and BL21 (DE3) used for protein

27 expression. Genes encoding pep86 tagged mitochondrial PCP proteins were cloned into either 28 pBAD or pRSFDuet. YPH499 yeast cells transformed with pYES2 containing the mt-11S gene 29 under control of the GAL promoter, were used for isolation of mitochondria containing matrix30 localised 11S. E. coli cells were routinely grown at $37^{\circ} \mathrm{C}$ on LB agar and in either LB or $2 X Y T$ 31 medium containing appropriate antibiotics for selection. Yeast cells were grown at $30^{\circ} \mathrm{C}$ on 
1 synthetic complete dropout agar supplemented with $2 \%$ glucose, penicillin and streptomycin, or

2 in synthetic complete dropout medium, supplemented with $3 \%$ glycerol, penicillin and

3 streptomycin in baffled flasks. For yeast cells with mitochondrial matrix-localised 11S, mt-11S

4 was expressed by adding $1 \%$ galactose at mid-log phase, 16 hours prior to harvesting of cells.

\section{Protein production and purification}

7 BL21 (DE3) cells from a single colony, containing the chosen protein expression plasmid were 8 grown in LB overnight then sub-cultured in $2 \mathrm{XYT}$ medium until $\mathrm{OD}_{600}$ reached 0.6. Protein expression was induced by adding arabinose or IPTG, for pBAD and pRSFDuet plasmids respectively. Cells were harvested 2-3 hours later and lysed using a cell disrupter. Proteins were

11 purified from inclusion bodies using Nickel affinity chromatography on prepacked HisTrap FF 12 columns (Cytiva), followed by ion exchange chromatography on either HiTrap Q HP or HiTrap 13 SP HP columns (Cytiva) depending on protein charge, described in full previously (Pereira et al., 14 2019).

\section{Isolation of mitochondria from yeast cells}

17 Yeast cells were harvested by centrifugation $(4,000 \times \mathrm{g}, 10 \mathrm{~min}$, room temperature) and mitochondria isolated by differential centrifugation (Daum et al., 1982). Briefly, cell walls were digested with zymolyase in phosphate-buffered sorbitol (1.2 M sorbitol, $20 \mathrm{mM}$ potassium phosphate $\mathrm{pH}$ 7.4), after being reduced with DTT (1 mM DTT in $100 \mathrm{mM}$ Tris-SO4 at pH 9.4, for

$2115 \mathrm{~min}$ at $30^{\circ} \mathrm{C}$ ). Cells were disrupted at $4^{\circ} \mathrm{C}$ with a glass Potter-Elvehjem homogeniser with motorised pestle in a standard homogenisation buffer $(0.6 \mathrm{M}$ sorbitol, $0.5 \%(\mathrm{w} / \mathrm{v}) \mathrm{BSA}, 1 \mathrm{mM}$ PMSF, $10 \mathrm{mM}$ Tris- $\mathrm{HCl} \mathrm{pH}$ 7.4). The suspension was centrifuged at low speed (1,480 x $\mathrm{g}, 5 \mathrm{~min})$

24 to pellet unbroken cells, cell debris and nuclei, and mitochondria harvested from the supernatant 25 by centrifugation at $17,370 \times \mathrm{g}$. The pellet, containing mitochondria, was washed in SM buffer 26 (250 mM sucrose and $10 \mathrm{mM}$ MOPS, $\mathrm{pH}$ 7.2), and then centrifuged at low speed again, to remove 27 remaining contaminants. The final mitochondrial sample, isolated from the supernatant by 28 centrifugation (17,370 x g, $15 \mathrm{~min}$ ), was resuspended in SM buffer and protein quantified by 29 bicinchoninic acid (BCA) assay (Smith et al., 1985) using a bovine serum albumin protein 30 standard. Mitochondria were stored at $-80^{\circ} \mathrm{C}$, at a concentration of at $30 \mathrm{mg} / \mathrm{ml}$ in single use 31 aliquots, after being snap frozen in liquid nitrogen. 
2 NanoLuc import assay

3 Unless stated otherwise, import experiments were performed at $25^{\circ} \mathrm{C}$ with $\mathrm{mt}-11 \mathrm{~S}$ mitochondria 4 diluted to $50 \mu \mathrm{g} / \mathrm{ml}$ in import buffer (250 mM sucrose, $80 \mathrm{mM} \mathrm{KCl}, 1 \mathrm{mM} \mathrm{K} 2 \mathrm{HPO}_{4} / \mathrm{KH}_{2} \mathrm{PO}_{4}, 5$ $5 \mathrm{mM} \mathrm{MgCl}_{2}, 10 \mathrm{mM}$ MOPS-KOH and 0.1\% (v/v) Prionex reagent (Merck), pH 7.2), supplemented 6 with $2 \mathrm{mM} \mathrm{NADH}, 1 \mathrm{mM} \mathrm{ATP}, 0.1 \mathrm{mg} / \mathrm{ml}$ creatine kinase, $5 \mathrm{mM}$ phosphocreatine, and $1 \mu \mathrm{M}$ 7 pep86-tagged PCP protein. We also added $10 \mu \mathrm{M}$ GST-Dark protein; a fusion of glutathione S8 transferase and a peptide with high affinity for 11S, that inhibits pep86 binding and concomitant enzymatic activity, and thereby reduces background signal caused by trace amounts of $11 \mathrm{~S}$ outside

10 of the mitochondrial matrix. Mitochondria and GST-Dark were added to $1 \mathrm{X}$ import buffer at 1.25X

11 final concentrations (mixture 1), and pep86-tagged PCP protein, NADH, ATP, creatine kinase and 12 phosphocreatine added to $1 \mathrm{X}$ import buffer at $5 \mathrm{X}$ final concentrations (mixture 2) so that import 13 reactions could be started by the injection of 4 vols mixture 1 onto 1 vol mixture 2 . In selected 14 experiments, depletion of $\Delta \psi$ was achieved by pre-treating mitochondria for 5 minutes with $10 \mathrm{nM}$ 15 valinomycin, and depletion of ATP was achieved by omitting ATP, creatine kinase and 16 phosphocreatine from the reaction. Luminescence was read from $125 \mu 1$ reactions in a white round17 bottom 96 well plate (Thermo Scientific) on either a CLARIOStar Plus (BMG LABTECH), or a 18 BioTek Synergy Neo2 plate reader (BioTek Instruments) without emission filters. The 19 mitochondrial matrix volume as a fraction of reaction volume was estimated using the previously 20 published yeast mitochondrial matrix volume of $1.62 \pm 0.3 \mu 1 / \mathrm{mg}$ (Koshkin and Greenberg, 2002).

21 Thus when mitochondria are at $50 \mu \mathrm{g} / \mathrm{ml}$, matrix volume will be $81 \pm 15 \mathrm{nl} / \mathrm{ml}$, or $\sim 1 / 12345.68$ total 22 volume (between $1 / 15151.5$ and $1 / 10416.7$ accounting for error).

\section{Data processing and analysis}

25 NanoLuc assay data were processed using a combination of software: Microsoft Excel, pro Fit and 26 GraphPad Prism. Data were then normalised to the maximum luminescence measurement for each 27 experiment.

In most cases, the resulting data were fitted using pro Fit to a model for two consecutive, irreversible steps, where the final one gives rise to a signal (Fersht, 1984):

$$
Y=A_{0}\left(1+\frac{1}{k_{1}-k_{2}}\left(k_{2} e^{-k_{1} t}-k_{1} e^{-k_{2} t}\right)\right.
$$


1 where $\mathrm{A}_{0}$ is amplitude, $k_{1}$ and $k_{2}$ the two rate constants, $\mathrm{Y}$ the signal and time. Note that this

2 equation produces the same result whichever order $k_{1}$ and $k_{2}$ are in. Subsequent analyses of the

3 resultant data were done in GraphPad Prism; linear and non-linear (Michaelis-Menten) regression.

5 Membrane potential measurements with isolated mitochondria

6 Isolated mitochondria were diluted to $50 \mu \mathrm{g} / \mathrm{ml}$ in import buffer (described above) supplemented

7 with $1 \mathrm{mM}$ ATP, $0.1 \mathrm{mg} / \mathrm{ml}$ creatine kinase, $5 \mathrm{mM}$ phosphocreatine, $10 \mu \mathrm{M}$ GST-Dark protein

8 and $0.5 \mu \mathrm{M}$ Tetramethylrhodamine methyl ester (TMRM). Relative $\Delta \psi$ was monitored over time

9 as a change in fluorescence of the $\Delta \psi$-dependent dye TMRM in quenching mode. Fluorescence

10 was measured at an excitation wavelength of $548 \mathrm{~nm}$ and an emission wavelength of $574 \mathrm{~nm}$, in

11 black plates, on a BioTek Synergy Neo2 plate reader (BioTek Instruments). The inner membrane

12 PMF was generated by injecting $2 \mathrm{mM} \mathrm{NADH}$, and PCP proteins added manually after

13 stabilisation of fluorescence.

15 Acknowledgments:

16 We would like to thank Prof. Andrew Halestrap for his insight and enthusiastic discussions on the

17 mysteries of mitochondrial bioenergetics. We also thank past and present members of the

18 Collinson lab who helped to get this project off the ground, particularly Drs Andrew Richardson

19 and Dylan Noone.

\section{Funding:}

22 This research was funded by the Wellcome Trust: Investigator Award to IC (104632/Z/14/Z).

\section{Author contribution:}

25 Project conceptualisation: GCP, HCF and IC

26 Sample preparation: HCF and XL

27 Data Collection: HCF

28 Data Analysis: HCF and WJA

29 Data interpretation: HCF, WJA and MSD 
1 Manuscript writing: $\mathrm{HCF}, \mathrm{WJA}$ and IC

2 Funding acquisition and project management: IC

3

\section{Declarations:}

5 The authors declare no competing interests. The funding agency and the University had no role in 6 study design, data collection and analysis, decision to publish, or preparation of the manuscript.

7 For the purpose of Open Access, the author has applied a CC BY public copyright licence to any 8 Author Accepted Manuscript version arising from this submission. 


\section{FIGURE LEGENDS:}

Figure 1: Model of PCP import into mitochondria and outline of the NanoLuc import assay

A) Simple model of presequence-containing precursor (PCP) import into mitochondria, showing binding of PCP to the TOM complex, $\Delta \psi$-dependent movement of the presequence into the matrix, ATP-dependent translocation of the remainder of the protein, and binding of the C-terminal pep86 to $11 \mathrm{~S}$ which forms NanoLuc in the matrix.

B) Diagramatic representation of the NanoLuc real-time import assay.

C) An example of luminescence data from the NanoLuc import assay, showing the fit to a model for two consecutive, irreversible steps (see Methods).

Figure 2: Basic characterisation of PCP import and turnover number

13 A) The effect of varying PCP concentration (Acp1-pep86) on signal amplitude. A straight line was 14 fitted to the data where amplitude increased linearly with PCP concentration (red), and to the data 15 where amplitude increased only marginally (blue). The intersect of these lines and corresponding 16 PCP concentration, the point of plateau, is also shown (purple).

17 B) The effect of MTX on signal amplitude of three proteins (depicted schematically below): Acp1DHFR-pep86 (purple), where MTX prevents entry of pep86; Acp1-pep86-DHFR (orange), where MTX limits import to one pep86 per import site; and Acp1-pep86 (grey), for which MTX should have no effect. Bars show the average and SEM from three independent biological replicates.

21 C) Signal amplitude as a function of Acp1-pep86-DHFR concentration in the absence (solid circles) and presence (open circles) of MTX.

Figure 3: Using proteins of varying lengths to elucidate import kinetics

A) Schematic of two protein series (length variants and sequence variants), with MTS in grey, mature Acp1 in red, pep86 in yellow (L for light) and scrambled pep86 in blue (D for dark).

B) Example of import traces for length variants (left panel) and sequence variants (right panel). Error bars show SD from biological triplicate, each conducted in duplicate.

C) Parameters obtained from two step fits to the data shown in panel B. The length series is shown

30 in orange and the sequence series in teal. Error bars show SEM from biological triplicate, each

31 conducted in duplicate. 
2 Figure 4: The concentration dependence of length and sequence variants

3 A-F) Amplitudes (A, D), $k_{1}{ }^{\prime}$, assigned as the faster rate $(\mathbf{B}, \mathbf{E})$ and $k_{2}{ }^{\prime}(\mathbf{C}, \mathbf{F})$ for the length $(\mathbf{A}-\mathbf{C})$

4 and sequence (D-F) series, coloured red, orange, yellow and green in order of increasing length or

5 pep86 position. All individual fits from 4-6 independent biological replicates of each set are

6 shown, and the secondary data are fitted to the Michaelis-Menten equation, with errors estimated

7 from the fitting.

Figure 5: Effects of energy depletion on transport of the length and sequence variants

10 A) Transport without (solid circles) or with (open circles) depletion of $\Delta \psi$, for the length (orange)

11 and sequence (teal) series. Plots show amplitude (left), $k_{1}{ }^{\prime}$ (middle) and $k_{2}{ }^{\prime}$ (right) extracted from

12 two-step fits to import traces as a function of PCP length or pep86 position. Each point is the

13 average and SEM of three independent biological replicates.

14 B) As in panel A, but without (solid circles) or with (open circles) ATP depletion instead of 15 valinomycin.

17 Figure 6: The effect of PCP charge on import kinetics

18 A) Overview of the charge variant protein series, showing numbers of positively (blue) and 19 negatively (red) charged residues, and symbols for each protein with colours corresponding to 20 theoretical pI, according to the scale shown on the left.

21 B) Import traces for the charge variant proteins in which the number of negative (left) and positive

22 (right) charges are varied, normalised to the native PCP, coloured by rainbow from most negative

23 (red) to most positive (violet). Data shown are a single representative trace; this is because starting 24 points for each data set are slightly offset due to the injection time of the plate reader. Full data 25 three biological replicates each performed in duplicate - are shown in Fig. S4A.

26 C) Amplitudes obtained from panel (B) as a function of net charge (coloured as in panel B), with 27 a line of best fit shown.

28 D) TMRM fluorescence over time with isolated yeast mitochondria (left), with PCPs added at the 29 time indicated by arrowhead. A no protein control (buffer only) is shown in grey, and the 30 remaining traces are shown with the PCP coloured as in panel B. Average TMRM fluorescence 31 over a 5 minute window (between orange lines) was calculated for each trace then plotted, relative 
1 to no protein control, against protein net charge (right). Data shown is mean \pm SD from three

2 biological repeats.

3 E) Amplitude (normalised to the native PCP in standard conditions) of import signal for the charge

4 variants, where numbers of negatively (left) or positively (right) charged residues is varied, under

5 standard reaction conditions (grey) or when $\Delta \psi$ (purple) or ATP (green) is depleted. Each data

6 point is the mean \pm SEM from three biological repeats (shown in Fig. S4B-C).

8 Figure 7: Transport of pep86 fused native precursors

9 A) Schematic representation of the four native precursors chosen: $F_{1} \alpha$ (long, positively charged),

$10 \quad \mathrm{~F}_{1} \beta$ (long, negatively charged), Mrp21 (short, positively charged) and Acp1 (short, negatively 11 charged).

12 B) Transport signal for the four proteins in panel A, normalised to Acp1. Each trace is the mean \pm 13 SD of three biological repeats.

\section{$15 \quad$ Figure S1: 11S levels and signal amplitude}

16 A) Western blot against 11S (bottom) and TOM40 (contro1, top) of eight different mitochondrial 17 preparations extracted from four different batches of yeast. $60 \mu \mathrm{g}$ each sample of mitochondria 18 was fractionated by SDS-PAGE prior to Western blot. Two known concentrations of purified his19 tagged 11S are also included for quantification by densitometry.

20 B) Import traces of Acp1-pep86 with each of the mitochondrial preps in panel A, performed in 21 parallel and unnormalised.

22 C) Signal amplitude from panel $\mathbf{B}$ as a function of $11 \mathrm{~S}$ concentration (normalised to TOM40) from panel A, with points coloured as in panel B. The results show no correlation between 11S concentration and amplitude.

Figure S2: Constraints of data fitting to the NanoLuc import traces.

27 A) The expected signal for a two-step transport process, with $k_{2}{ }^{\prime}$ fixed at $0.5 \mathrm{~min}^{-1}$ and $k_{1}{ }^{\prime}$ varied 28 between $0.1 \mathrm{~min}^{-1}$ (red) and $12.8 \mathrm{~min}^{-1}$ (magenta). As $k_{1}{ }^{\prime}$ increases, it makes increasingly less 29 difference to the overall shape of the curve. Because the plate reader measures luminescence with 30 a frequency of $10 \mathrm{~min}^{-1}$ (represented as vertical gridlines in the zoomed in panel, right), any rate 
1 constants faster than about $5 \mathrm{~min}^{-1}$ will not be resolved. The same effect holds true for any

2 additional rates that form part of the mechanism but are faster than $\sim 5 \mathrm{~min}^{-1}$.

3 B) Amplitude (blue) and rate (green) determined from a single exponential fits to NanoLuc

4 formation is solution. Substrate (pep86) is provided in the form of GST-pep86 which is not a PCP,

5 and $11 \mathrm{~S}$ comes from mitochondria solubilised completely with digitonin $(5 \mathrm{mg} / \mathrm{ml})$ to simulate

6 binding within the mitochondrial matrix. Fits are to the Michaelis Menten equation giving an

7 affinity of $15.6 \mathrm{nM}$ and a $v_{\max }$ of $7.4 \mathrm{~min}^{-1}$.

8 C) The import traces in Fig. S1B all normalised to 1, coloured in the same way. The fact that all

9 the traces overlay well confirms that binding of $11 \mathrm{~S}$ is too fast to constitute either of the rates

10 extracted from the two step fits - as expected given that the binding rate should be close to $v_{\max }$

11 for NanoLuc formation (as determined in panel B).

13 Figure S3. Confirmation of ATP depletion in the mitochondrial matrix.

14 Import traces for Acp1-pep86 (left) and Mrp21-pep86 (right) in the presence (filled circles) or 15 absence (open circles) of ATP and its regenerating system, and the absence (red and blue) or 16 presence (orange and lilac) of antimycin A (AA).

18 Figure S4. Complete import traces for the data in Fig. 6.

19 A) Two technical repeats each of three biological replicates, under standard conditions.

20 B) Three biological replicates with $\Delta \psi$ depletion (valinomycin)

21 C) Three biological replicates with ATP depletion. 


\section{REFERENCES:}

2 Allen WJ, Watkins DW, Dillingham MS, Collinson I. 2020. Refined measurement of SecAdriven protein secretion reveals that translocation is indirectly coupled to ATP turnover. Proc Natl Acad Sci U S A 117:31808-31816.

Araiso Y, Tsutsumi A, Qiu J, Imai K, Shiota T, Song J, Lindau C, Wenz LS, Sakaue H, Yunoki K, Kawano S, Suzuki J, Wischnewski M, Schütze C, Ariyama H, Ando T, Becker T, Lithgow T, Wiedemann N, Pfanner N, Kikkawa M, Endo T. 2019. Structure of the mitochondrial import gate reveals distinct preprotein paths. Nature 575:395-401.

Bauer MF, Sirrenberg C. 1996. Role of Tim23 as Voltage Sensor and Presequence Receptor in Protein Import into Mitochondria. Cell 87:33-41

Blom J, Kubrich M, Rassow J, Voos W, Dekker PJT, Maarse AC, Meijer M, Pfanner2 N, Maarse JC, Blom LA, Grivell M, Meijer J. 1993. The Essential Yeast Protein MIM44 (encoded by MPI) Is Involved in an Early Step of Preprotein Translocation across the Mitochondrial Inner Membrane The essential yeast gene MPI1 encodes a mitochondrial membrane protein that is possibly involved in protein. Mol Cell Biol 13:7364-7371.

Bragoszewski P, Wasilewski M, Sakowska P, Gornicka A, Böttinger L, Qiu J, Wiedemann N, Chacinska A. 2015. Retro-translocation of mitochondrial intermembrane space proteins. Proc Natl Acad Sci U S A 112: 7713-7718.

Callegari S, Cruz-Zaragoza LD, Rehling P. 2020. From TOM to the TIM23 complex - handing over of a precursor. Biol Chem 401:709-721.

Campanella M, Casswell E, Chong S, Farah Z, Wieckowski MR, Abramov AY, Tinker A, Duchen MR. 2008. Regulation of Mitochondrial Structure and Function by the F1FoATPase Inhibitor Protein, IF1. Cell Metab 8:13-25.

Chacinska A, Rehling P, Guiard B, Frazier AE, Schulze-Specking A, Pfanner N, Voos W, Meisinger C. 2003. Mitochondrial translocation contact sites: separation of dynamic and stabilizing elements in formation of a TOM-TIM-preprotein supercomplex. EMBOJ 22:5370.

Chacinska A, van der Laan M, Mehnert CS, Guiard B, Mick DU, Hutu DP, Truscott KN, Wiedemann N, Meisinger C, Pfanner N, Rehling P. 2010. Distinct Forms of Mitochondrial TOM-TIM Supercomplexes Define Signal-Dependent States of Preprotein Sorting. Mol Cell Biol 30:307-318. 
1 Chandel NS. 2015. Evolution of Mitochondria as Signaling Organelles. Cell Metab 22:204-206.

2 Chen Q, Vazquez EJ, Moghaddas S, Hoppel CL, Lesnefsky EJ. 2003. Production of reactive oxygen species by mitochondria: Central role of complex III. J Biol Chem 278:3602736031.

Daum G, Böhni PC, Schatz G. 1982. Import of proteins into mitochondria. Cytochrome b2 and cytochrome c peroxidase are located in the intermembrane space of yeast mitochondria. $J$ Biol Chem 257:13028-13033.

Dekker PJT, Martin F, Maarse AC, Bömer U, Müller H, Guiard B, Meijer M, Rassow J, Pfanner N. 1997. The Tim core complex defines the number of mitochondrial translocation contact

Demishtein-Zohary K, Günsel U, Marom M, Banerjee R, Neupert W, Azem A, Mokranjac D. sites and can hold arrested preproteins in the absence of matrix Hsp70-Tim44. EMBO J

Donzeau M, Káldi K, Adam A, Paschen S, Wanner G, Guiard B, Bauer MF, Neupert W, Brunner M. 2000. Tim23 links the inner and outer mitochondrial membranes. Cell 101:401412.

Fersht A. 1984. Enzyme Structure and Mechanism.

Geissler A, Krimmer T, Bö mer U, Guiard B, Rassow J, Pfanner N. 2000. Membrane PotentialDriven Protein Import into Mitochondria The Sorting Sequence of Cytochrome b 2 Modulates the-Dependence of Translocation of the Matrix-targeting Sequence. Molecular Biology of the Cell 11:3977-3991

Gold VA, Chroscicki P, Bragoszewski P, Chacinska A. 2017. Visualization of cytosolic ribosomes on the surface of mitochondria by electron cryo-tomography. EMBO Rep 18:1786-1800.

Gold VAM, Ieva R, Walter A, Pfanner N, Van Der Laan M, Kühlbrandt W. 2014. Visualizing active membrane protein complexes by electron cryotomography. Nat Commun 5:4129. 
1 Harner M, Neupert W, Deponte M. 2011. Lateral release of proteins from the TOM complex into

Hartl FU, Lecker S, Schiebel E, Hendrick JP, Wickner W. 1990. The binding cascade of SecB to SecA to SecY E mediates preprotein targeting to the E. coli plasma membrane. Cell 63:269-279.

Horst M, Hilfiker-Rothenfluh S, Oppliger W, Schatz G. 1995. Dynamic interaction of the protein

Hoth M, Fanger CM, Lewis RS. 1997. Mitochondrial regulation of store-operated calcium signaling in T lymphocytes. J Cell Biol 137:633-648.

Hwang S, Jascur T, Vestweber D, Pon L, Schatz G. 1989. Disrupted yeast mitochondria can import precursor proteins directly through their inner membrane. J Cell Biol 109:487-493.

Koshkin V, Greenberg ML. 2002. Cardiolipin prevents rate-dependent uncoupling and provides osmotic stability in yeast mitochondria. Biochem $J$ 364:317.

Lill R, Stuart RA, Drygas ME, Nargang FE, Neupert W. 1992. Import of cytochrome c heme lyase into mitochondria: a novel pathway into the intermembrane space. EMBO J 11:449456.

Maarse AC, Blom J, Grivell LA, Meijer M. 1992. MPI1, an essential gene encoding a mitochondrial membrane protein, is possibly involved in protein import into yeast mitochondria. EMBO J11:3619-3628.

Maarsea AC, Blom J, Keilb P, Pfannerb N, Meijer M. 1994. Identification of the essential yeast protein MIM17, an integral mitochondrial inner membrane protein involved in protein import. FEBS Lett 349:15-22.

Martin J, Mahlke K, Pfanner N. 1991. Role of an energized inner membrane in mitochondrial protein import: $\Delta \Psi$ drives the movement of presequences. J Biol Chem 266:18051-18057.

Matouschek A, Azem A, Ratliff K, Glick BS, Schmid K, Schatz G. 1997. Active unfolding of precursor proteins during mitochondrial protein import 16:6727-6736.

Mayer A, Lill R, Neupert W. 1993. Translocation and insertion of precursor proteins into isolated outer membranes of mitochondria. J Cell Biol 121:1233-1243.

Neupert W, Brunner M. 2002. The Protein Import Motor of Mitochondria. Nature Reviews Molecular Cell Biology 3:555-565 
1 Neupert W, Herrmann JM. 2007. Translocation of Proteins into Mitochondria. Annual Review of Biochemistry 76:1, 723-749

Nicholls DG. 1978. The regulation of extramitochondrial free calcium ion concentration by rat

Nishikawa T, Edelstein D, Du XL, Yamagishi SI, Matsumura T, Kaneda Y, Yorek MA, Beebe D, Oates PJ, Hammes HP, Glardino I, Brownlee M. 2000. Normalizing mitochondrial superoxide production blocks three pathways of hyperglycaemic damage. Nature 404:787790.

Nowinski SM, Van Vranken JG, Dove KK, Rutter J. 2018. Impact of Mitochondrial Fatty Acid Synthesis on Mitochondrial Biogenesis. Curr Biol 28:R1212-R1219

Ohba M, Schatz G. 1987. Disruption of the outer membrane restores protein import to trypsintreated yeast mitochondria. EMBO J 6:2117-2122.

Pereira GC, Allen WJ, Watkins DW, Buddrus L, Noone D, Liu X, Richardson AP, Chacinska A, Collinson I. 2019. A High-Resolution Luminescent Assay for Rapid and Continuous Monitoring of Protein Translocation across Biological Membranes. J Mol Biol 431:16891699.

Ramesh A, Peleh V, Martinez-Caballero S, Wollweber F, Sommer F, Laan M van der, Schroda M, Alexander RT, Campo ML, Herrmann JM. 2016. A disulfide bond in the TIM23 complex is crucial for voltage gating and mitochondrial protein import. J Cell Biol 214:417.

Rassow J, Guiard B, Wienhues U, Herzog V, Hartl FU, Neupert W. 1989. Translocation arrest by reversible folding of a precursor protein imported into mitochondria. A means to quantitate translocation contact sites. J Cell Biol 109:1421-1428.

Rassow J, Hartl FU, Guiard B, Pfanner N, Neupert W. 1990. Polypeptides traverse the mitochondrial envelope in an extended state. FEBS Lett 275:190-194.

Rouault TA. 2012. Biogenesis of iron-sulfur clusters in mammalian cells: New insights and relevance to human disease. DMM Dis Model Mech 5:155-164

Martinez-Caballero S, Grigoriev SM, Herrmann JM, Campo ML, Kinnally KW. 2007. Tim17p regulates the twin pore structure and voltage gating of the mitochondrial protein import complex TIM23. J Biol Chem 282:3584-3593.

Schendzielorz AB, Schulz C, Lytovchenko O, Clancy A, Guiard B, Ieva R, van der Laan M, Rehling P. 2017. Two distinct membrane potential-dependent steps drive mitochondrial 
matrix protein translocation. $J$ Cell Biol 216:83-92.

2 Sirrenberg C, Endres M, Becker K, Bauert MF, Walther E, Neupert W, Brunner M. 1997.

Functional cooperation and stoichiometry of protein translocases of the outer and inner membranes of mitochondria. J Biol Chem 272:29963-29966.

Smith PK, Krohn RI, Hermanson GT, Mallia AK, Gartner FH, Frovenzano MD, Fujimoto EK, Goeke NM, Olson BJ, Klenk DC. 1985. Measurement of Protein Using Bicinchoninic Acid. Analytical Biochemistry 150:76-85

Ting SY, Yan NL, Schilke BA, Craig EA. 2017. Dual interaction of scaffold protein Tim44 of mitochondrial import motor with channel-forming translocase subunit Tim23. Elife 6.e23609

Truscott KN, Kovermann P, Geissler A, Merlin A, Meijer M, Driessen AJM, Rassow J, Pfanner

Vögtle FN, Wortelkamp S, Zahedi RP, Becker D, Leidhold C, Gevaert K, Kellermann J, Voos N, Wagner R. 2001. A presequence- and voltage-sensitive channel of the mitochondrial preprotein translocase formed by Tim23. Nat Struct Biol 2001 812 8:1074-1082.

Tucker K, Park E. 2019. Cryo-EM structure of the mitochondrial protein-import channel TOM complex at near-atomic resolution. Nat Struct Mol Biol 26:1158-1166.

Ungermann C, Guiard B, Neupert W, Cyr DM. 1996. The $\Delta \Psi$ - and Hsp70/MIM44-dependent reaction cycle driving early steps of protein import into mitochondria. EMBO J 15:735-744.

Wang C, Youle RJ. 2009. The role of mitochondria in apoptosis. Annu Rev Genet 43:95-118 
bioRxiv preprint doi: https://doi.org/10.1101/2021.08.30.458282; this version posted August 31, 2021. The copyright holder for this preprint (which was not certified by peer review) is the author/funder, who has granted bioRxiv a license to display the preprint in perpetuity. It is made available under aCC-BY 4.0 International license.

Fig 1.
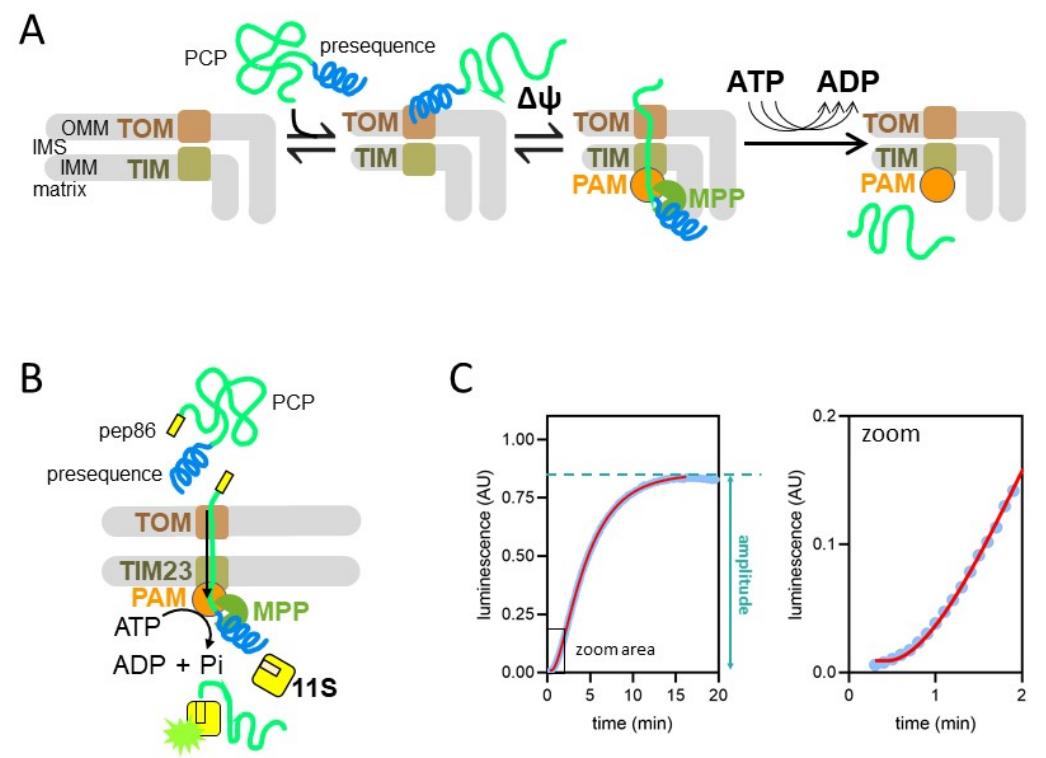

Fig 2. A
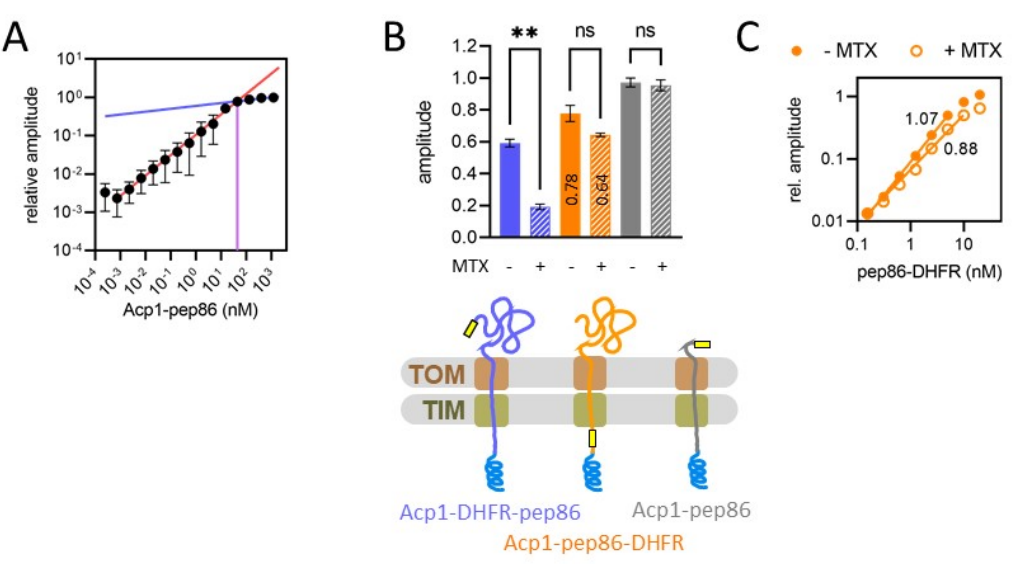
bioRxiv preprint doi: https://doi.org/10.1101/2021.08.30.458282; this version posted August 31, 2021. The copyright holder for this preprint (which was not certified by peer review) is the author/funder, who has granted bioRxiv a license to display the preprint in perpetuity. It is made available under aCC-BY 4.0 International license.

Fig 3. A

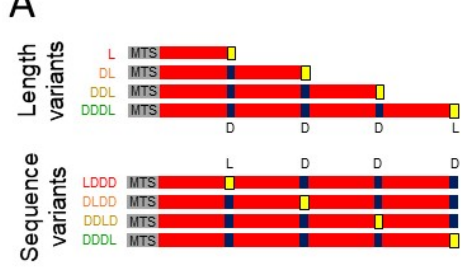

B

C
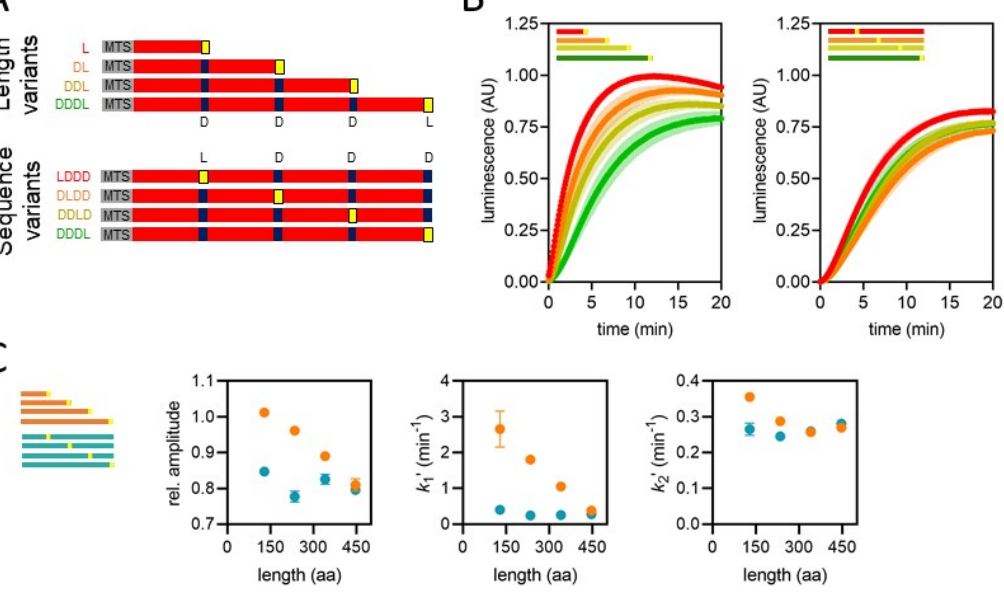

\section{Fig 4}

$A \equiv$

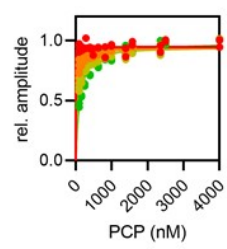

B

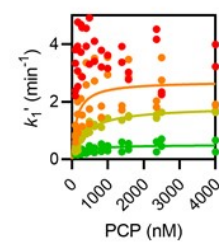

C
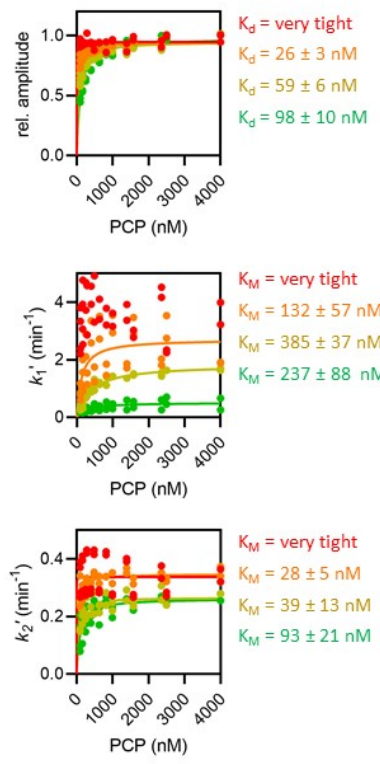

$\mathrm{K}_{\mathrm{M}}=$ very tight

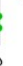

$\mathrm{D} \equiv$ $K_{M}=132 \pm 57 \mathrm{nM}$ $\mathrm{K}_{\mathrm{M}}=385 \pm 37 \mathrm{nM}$ $K_{M}=237 \pm 88 \mathrm{nM}$

(2)

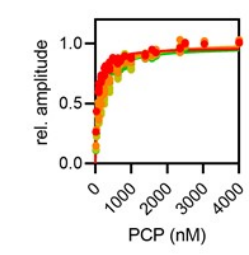

$\mathrm{E}$
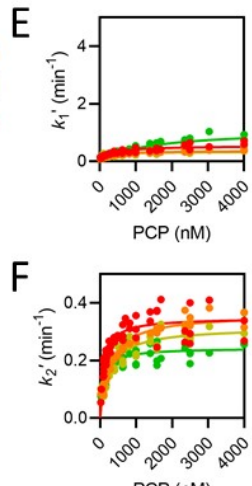

$K_{M}=104 \pm 15 \mathrm{nM}$

$K_{M}=266 \pm 20 \mathrm{nM}$

$K_{M}=250 \pm 30 \mathrm{nM}$

$K_{M}=102 \pm 14 \mathrm{nM}$ 
bioRxiv preprint doi: https://doi.org/10.1101/2021.08.30.458282; this version posted August 31, 2021. The copyright holder for this preprint (which was not certified by peer review) is the author/funder, who has granted bioRxiv a license to display the preprint in perpetuity. It is made available under aCC-BY 4.0 International license.

Fig 5.
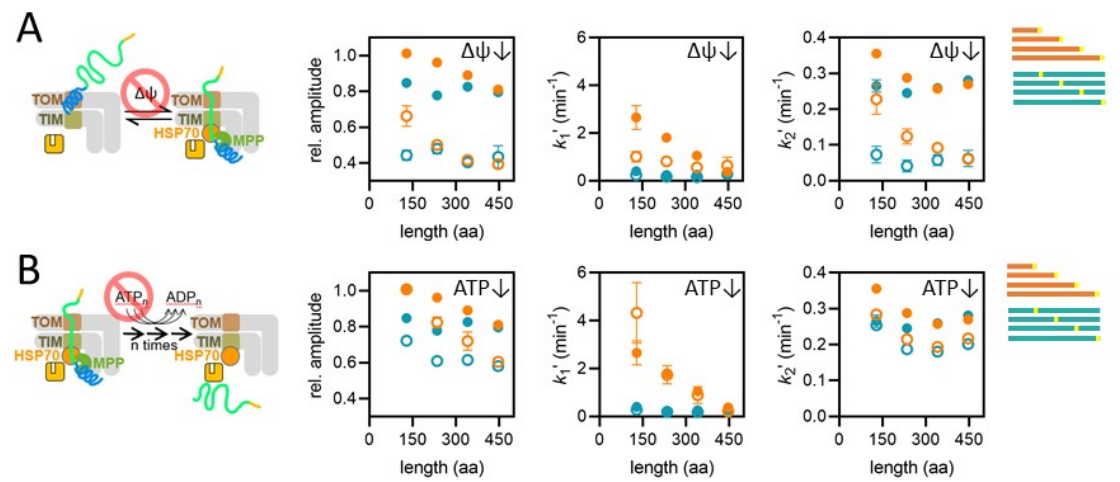

Fig 6.

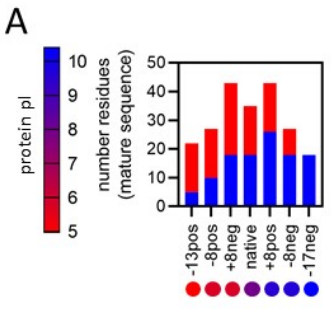

B varying negative charges

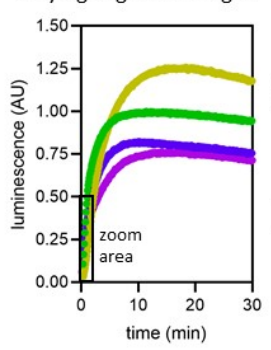

C

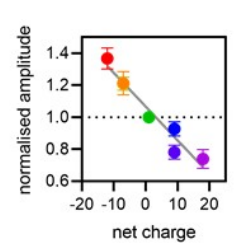

D

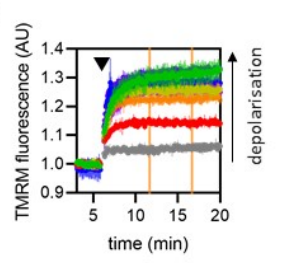

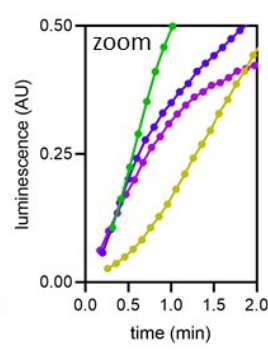
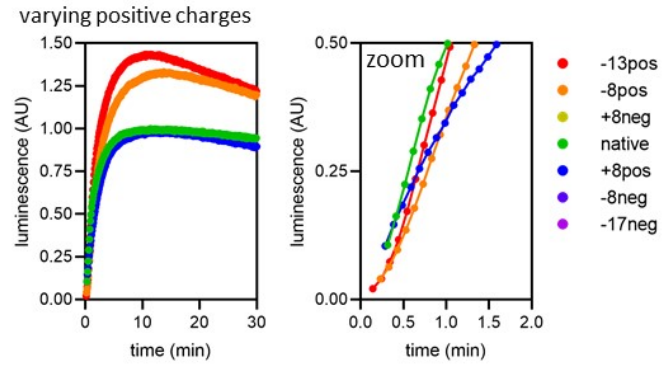

E

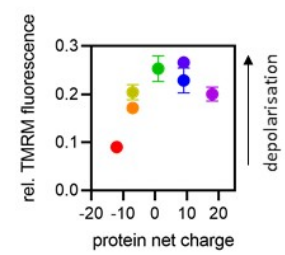

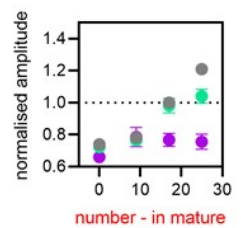

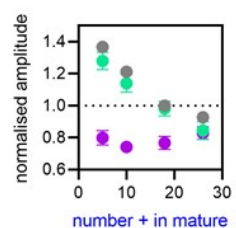


bioRxiv preprint doi: https://doi.org/10.1101/2021.08.30.458282; this version posted August 31, 2021. The copyright holder for this preprint (which was not certified by peer review) is the author/funder, who has granted bioRxiv a license to display the preprint in perpetuity. It is made available under aCC-BY 4.0 International license.

Fig 7.
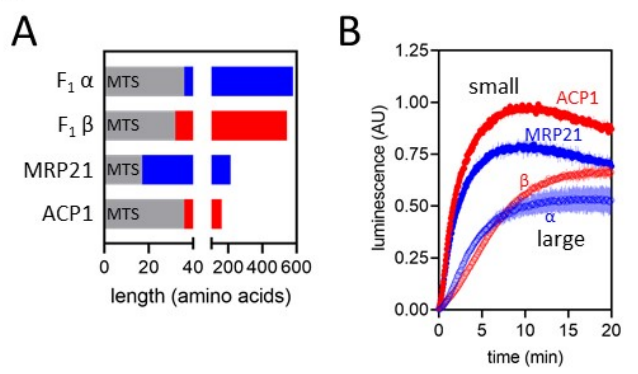

Fig S1.

A

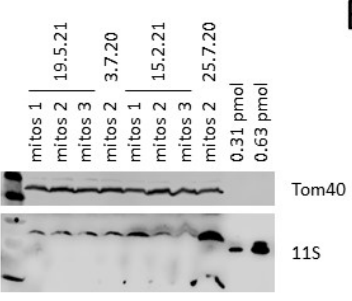

B

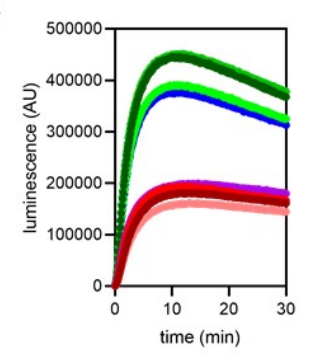

C

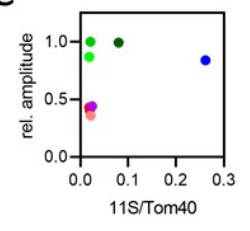

Fig S2.

A
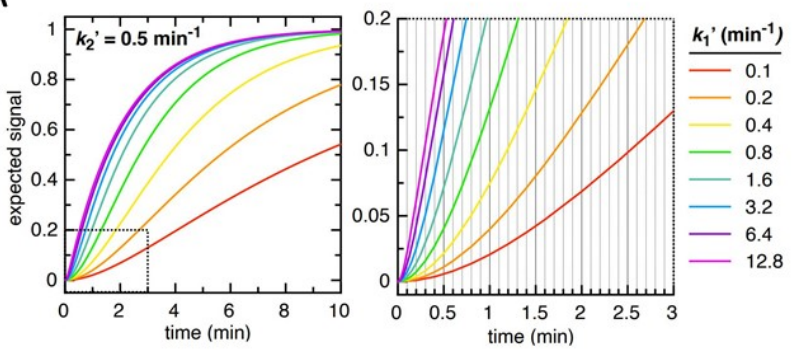

B

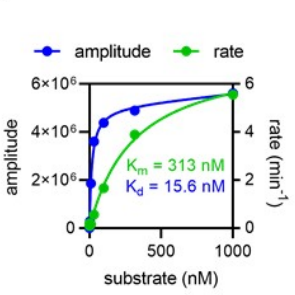

C

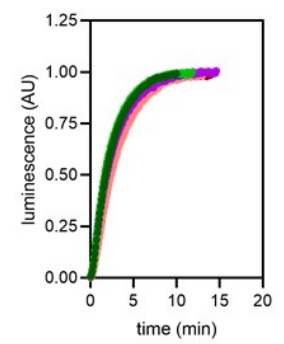

Fig S3.
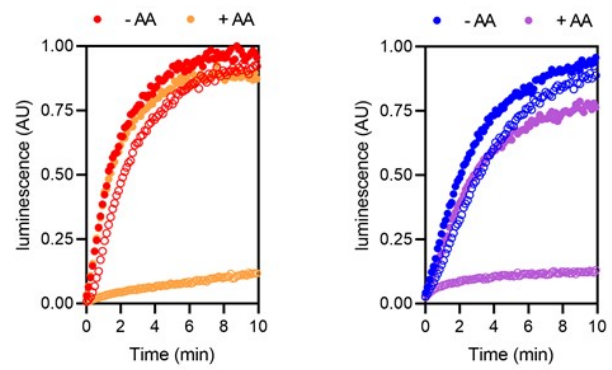
bioRxiv preprint doi: https://doi.org/10.1101/2021.08.30.458282; this version posted August 31, 2021. The copyright holder for this preprint (which was not certified by peer review) is the author/funder, who has granted bioRxiv a license to display the preprint in perpetuity. It is made available under aCC-BY 4.0 International license.

\section{Fig S4.}
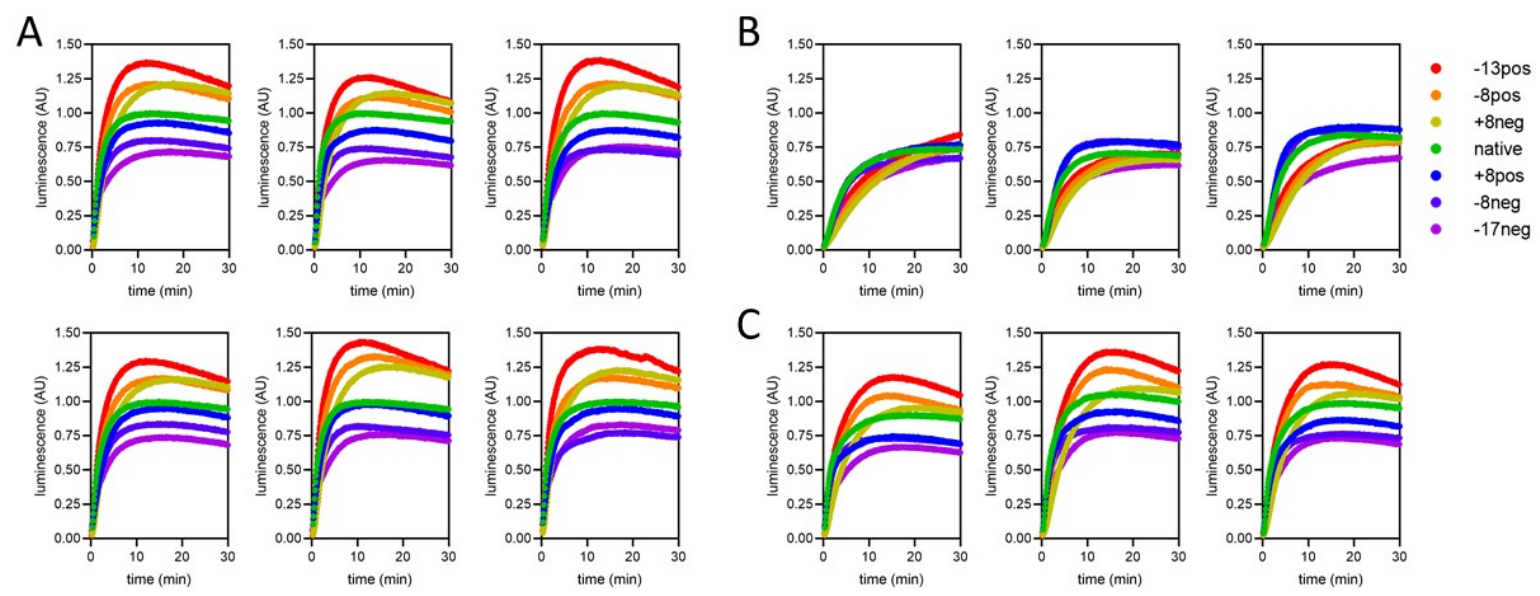

C
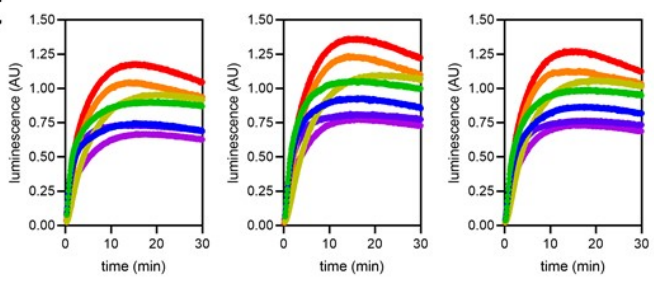